\title{
Work Intensification: A Stumbling Block to Work Life Balance?
}

\author{
Aaliya Abdoolla, Patsy Govender \\ Faculty of Law and Management Studies, University of KwaZulu-Natal, Durban, South Africa \\ govenderpa@ukzn.ac.za
}

\begin{abstract}
Of recent, studies on work intensification have surfaced in many sectors of the work environment and, with work-life balance being triggered by numerous variables. Employees are working harder and faster to meet tight deadlines and the speed of work has escalated resulting in a negative association with their health. The study aims to assess whether work intensification hinders work-life balance and affects employees' daily tasks. A quantitative approach was selected for the study and, both descriptive and inferential statistics were utilized. Hypotheses testing were part of the study and most were partially accepted. The simple random sample was chosen and a sample of 100 employees was drawn. Data were collected using a self-developed questionnaire. The results showed that work intensification and work-life balance occurred at varying degrees and improvements were required in several areas. The adverse results of work intensification and high-involvement work processes have a tremendous impact on the employees' work-life balance. The study culminates with a projection on recommendations, conclusion and, practical implications are reflected upon based on the study.
\end{abstract}

Keywords: Work intensification, work intensity, work demands, work-life balance, working conditions

\section{Introduction}

Today's organizations strive to change their work patterns to align with the changing world of work and to meet both strategic goals and competitive challenges. These pressures intensify the demand for employees' performance optimization. Intense work pressures, cost factors and, work intensification has affected the psychological well-being of employees and; meeting deadlines, long work hours, working at a faster pace and technological changes, amongst others, are often the underlying causes of work intensification. Work life balance, a core component for quality of life, balances the demands of a person's work and family responsibilities. In line with this, jobs are placing value on knowledge than physical skill (O'Connor, 2005) and employees' work demands have become more mental than physical (Naswall, Hellgren \& Sverke, 2008). During the 1990's, work intensification was an important feature of the European labour markets (Burchell, Lapido \& Wilkinson, 2002; Green, 2001; Green \& McIntosh, 2001). Studies on labour intensive industries and high performance work systems have contributed to work intensification. Work intensification is the pace needed in a job (intensive work intensification) or the number of hours required in a job (extensive work intensification) (Green, 2001). It is also associated with employee stress, reduced job satisfaction, workplace injuries and employee health, amongst others (Burchell et al., 2002). According to Green (2004), limited research on work intensification is because of the scarcity of usable measures of work effort and, the origins of work intensification are beginning to accumulate (Green, 2004). Work effort involves employees' physical and/or mental input with work task performance (Burchell et al., 2002). Information technology too has contributed to information overload, including a faster pace of working (Sparks, Faragher \& Cooper, 2001) with technological advancements affecting manual labour (Naswall et al., 2008). Today, work intensification is evident with office-based employees too.

The social aspect with work and family is linked to changes in the nature of employment (Crompton, 2006) and, the transition to the new economy has resulted in shifting boundaries between work and home (James, 2011).Work-life balance safeguards a well-functioning interaction between the life roles and, achieving an acceptable balance is subjective to perceptions which is conducive to peoples' circumstances (Nitzsche, Pfaff, Jung \& Driller, 2013). Of recent, organizations are becoming more flexible as the attention with work-life balance is on the equilibrium in both roles with emphasis on the level of involvement, amount of time and individual satisfaction (Voydanoff, 2007) and, require constant negotiation between role demands as employees strive for financial security. Organizational assistance provides training and support to employees to cope with work-related and non-work related demands such as, parental training and childcare facilities (de Klerk \& Mostert, 2010). The aim is to have a win-win solution for organizations and employees. A balance 
in quality of work life brings about organisational productivity and with employees being satisfied with their personal needs.

The study is important for many reasons. Firstly, the aim is to show that the study can be conducted in organizations other than labour intensive ones. Secondly, organizations strive to fuel their growth objectives by investigating factors that contribute to work intensification, taking corrective actions to rectify this; and instituting programmes to balance employees' work and personal domains and to enhance employees' overall well-being by creating a less intense work environment. In this way, companies can be productive and adapt to the requirements of a global nature. The paper aims to investigate whether work intensification is a stumbling block on work-life balance in a public sector organization. The key variables for work intensification (organizational and technological change, work intensity and ergonomic factors, work-related stress and psychological factors, volume of workload and job insecurity) and for work-life balance (workfamily conflict, work flexibility, managerial/supervisory support, child/elderly care and employee wellness) will be explored in the study.

\section{Literature Review}

Organizational change: In today's work environment, one cannot obliterate the brutal recessionary period and, organizational changes have been driven by changing legislation, globalization and technological changes. Organizations have a radically transformed workforce that is diverse, highly global, virtual and empowered and; decision-making is decentralized, establishing more fluid and flatter organizational structures (Tucker, Kao, \& Verma, 2005). In the lower hierarchical structures, workers take decisions instead of managers (Tucker et al., 2005). The volatile market compels organizations to align the demand and supply of labour by employing strategies (Burchell et al., 2002), firstly, to build a workforce with both core (permanent) workers and peripheral temps and then to attempt to vary the length and intensity of the hours employees worked (temporal flexibility) (Burchell et al., 2002). Functional flexibility has become more prevalent (Burchell et al., 2002), whereby the labour force shows versatility in taking many and differing work tasks due to circumstances (Atkinson, 1984 cited in Allvin, Aronsson, Hagström, Johansson \& Lundberg, 2011).

Technological change: Technological change creates market expansion, competition, better quality of products and services, including new decision-making processes in a knowledge-based economy. Hence, a need exists for new managerial styles on control and the management of processes. Globally situated companies have promoted an electronic mail (e-mail) culture which has consequences for employees (Waller \& Ragsdell, 2012) and, creates stress due to e-mail-related pressure (Hair, Renaud \& Ramsay, 2007 cited in Waller \& Ragsdell, 2012). The advantages of e-mail are cost savings, speed, storing and processing information, locational flexibility and increased access to new people, amongst others (Waller \& Ragsdell, 2012); whereas the disadvantages include lack of confidentiality with message interception, and system and information overload (Waller \& Ragsdell, 2012). So, employees work faster, do more and others may engross themselves into their work and/or technology as their only priority (Porter \& Kakabadse, 2006) The theory of flow perspective shows that a person's mindset facilitated by information technology leads to intense involvement in an activity that nothing else seems to matter (Porter \& Kakabadse, 2006).

Work intensity and ergonomic factors: The impact of work intensity on employee well-being which impacts on families, co-workers, and the organisation has the potential to disrupt the efficient functioning of business and threaten the organisation's financial viability (Burke et al., 2010). Managerial control strategies include the redesign of job tasks and the implementation of new control technologies to increase the pace of work and performance quality (Beynan, Grimshaw, Rubery \& Ward, 2002 cited in Burchielli, Pearson \& Thanacoody, 2006). Burke, Singh and Fiksenbaum (2010) projects on internal personal factors and external environmental factors that drive work intensity. Ergonomics which is associated with safety, well-being and performance optimizes employees' working conditions (Down, 2001). Thus, their emotional well-being and physical activity need a supporting work climate (May, Reed, Schwoerer, \& Potter, 2004). Health problems and occupational disorders relate to long working hours of sitting (Alnaser \& Wughalter, 2009) and, ergonomics optimizes the interaction between employees' and their working environment (Pile, 2001), including the interaction between people and the work system as in the positioning of computer equipment 
which affects posture and eye fatigue (Down, 2001).Of recent, the concept of dynamic sitting in the development of office chairs has been encouraged (Dainoff, 2007) as ergonomic chairs accommodate several adjustable features (Alnaser \& Wughalter, 2009).

Work-related stress and psychological factors: Stress is characterized by the sources of workplace stress, an employee's perceptions and appraisals of a particular stressor and; with threatening stressors, the emotional aspect is reaction evoked (Rothmann, 2008). Job related stress stems from work-related factors (van Zyl,van Eeden, \& Rothmann, 2013) and; stress takes the form of being debilitative or facilitative (Barrett \& Campos, 1991 cited in Walinga \& Rowe, 2013). Van Zyl et al. (2013) cite decreased productivity, changes in work attitudes, low morale and increased absenteeism, as the symptoms of stressed employees. Stressors are linked with work circumstances, including a person's characteristics, resources and the social environment (Baba, Jamal \& Tourigny, 1998 cited in Pasca \& Wagner, 2011). Work intensification is theorized according to a stressor-stress-strain framework, whereby the intensification of work is conceptualized as the stressor leading to stress, resulting in psychological, behavioral or physiological strains (Burchell et al., 2002). Burnout which develops with high work stress levels influences individual job performance negatively (Huang, Du, Chen, \& Huang, 2011) and is characterized by emotional exhaustion, increased mental distance from one's job (cynicism), and reduced professional work efficacy (Nitzsche et al., 2013).

Volume of workload: High workloads which are negatively associated with job satisfaction have a positive association with job-related anxiety, exhaustion and work-related depression (Burchell et al., 2002). Sonnentag and Bayer (2005) emphasize two specific workload types that are, chronic workload and day specific workload in a work environment. Workload is detrimental to quality of work life (Sue Ling, Chang \& Lien Yin, 2012) and, the outcomes of workload manifests in physical and psychological health. With a reduction in irregular working and multi-tasking the resultant effect is reduced performance (Subramanyam et al., 2013). The psychological stressors of having to work fast, having conflicting demands and the amount of physical labour used is perceptual workload. With an imbalance between worker demands and abilities, the higher the level of stress (Rehman, Haq, Jam, Ali \& Hijazi, 2010). This imbalance is a poor fit between the work environment and the ability to tackle work situations due to excessive demands or the individual not being fully prepared to handle the situation (Rehman et al., 2010).

Job insecurity: Job insecurity, which contributes to feelings of helplessness (De Witte, 2005) is defined as the perceived threat of job loss and concern related to that threat (Sverke, Hellgren, Näswall, Chirumbolo, De Witte \& Goslinga, 2004).The antecedents of job insecurity are divided into variables on a macro level, for example region; individual characteristics, for example, age and occupational level; and personality traits (de Witte, 2005). Job insecurity and the concern about job loss (van Zyl et al., 2013) is viewed in the context of change and is the phase preceding unemployment (Van Wyk \& Pienaar, 2008). With quantitative job insecurity, the worry is about losing the job itself, whereas qualitative job insecurity relates to losing important features of the job, such as, a decline in working conditions or a lack of career opportunities (Sverke \& Hellgren, 2002 cited in Dachapalli \& Parumasur, 2012). Prolonged job insecurity is detrimental to the workers psychological well-being and concern is about the trauma of future job loss (Burchell et al., 2002).

Work-family conflict: Family friendly organizational arrangements, such as, flexible working hours and childcare arrangement, amongst others (Allvin et al., 2011) accommodates work and family demands. People face high demands in life spheres (Allvin et al., 2011) and working longer hours results in a more aggravated work-family conflict (Matthews, Swody \& Barnes-Farrell, 2012). Conflict is evident when work demands exceed resources contributing to a state of disequilibrium with work and home domains, resulting in psychological, emotional and physical strain (McNamara, Pitt-Catsouphes, Matz-Costa, Brown \& Valcour, 2013). The more hours an individual works, the less satisfaction there is with work-family balance (McNamara et al., 2013). Longer working hours increases the negative spillover from the work environment to the home (Dillworth, 2004; Kinnunen, Geurts \& Mauno, 2004 cited in Forma, 2009).

Work flexibility: Increased flexibility in the labour market has become a necessity (Goulding \& Kerslake, 1996) and, changes in the work environment impacts on occupational stress levels (Webber, Sarris \& Bessell, 2010). According to Naswall et al. (2008), the conditions of work have become boundaryless, implying a de- 
regulation or re-regulation. The increased flexibility of when and where work can be performed bares the risk of embarking on home life and creates an imbalance between work and non-work roles (Naswall et al., 2008). Work obligations shift from a company's authoritative rules to the individual and increases the responsibility for the work performed (Naswall et al., 2008). High job flexibility allows for work-life interaction and a state of balance, whereas low job flexibility limits this and creates conflict and imbalance (Webber et al., 2010). Additionally, the value of flexibility has the potential to diminish the benefits of flexibility (Lawton, 2010). Flexible working arrangements can have low rates of utilization due to employee fear on the adverse effects on their careers (McNamara et al., 2013). Yet, Hannabuss (1998) argues that flexible working patterns are advantageous for employers than employees.

Managerial/supervisory support: Helpful supervisors can have a positive effect on work-life balance (Singh, 2013) by reducing the negative spill-over from the work to the personal domain, and hence decrease work-life conflict (Chan, 2009 cited in Singh, 2013). Therefore, their support is linked with diminished worklife conflict (Anderson, Coffey \& Byerly, 2002; Hammer, Kossek, Zimmerman \& Daniels, 2007 cited in Lauzun, Morganson, Major \& Green, 2010) and, can be more effective than formal organizational policies that provide work-family support in understanding the variances in the affective, intentional and behavioral outcomes in employees (Behson, 2005). They create an environment that encourages balance (Lauzun et al., 2010) and, provide emotional support (caring and empathic understanding) including a flexible work schedule (Lauzun et al., 2010). Their support relates to resources and to solve work-related problems and express concern for employees non-work-related problems (Tayfur \& Arslan, 2013).

Child/elderly care: With childcare assistance, there are benefits with improved retention, increased performance and productivity (Babu \& Raj, 2013).Mothers are more likely to be at home with a sick child (Northcott, 1983 cited in Babu \& Raj, 2013) and are often absent from work. Caring for elderly dependents requires the satisfaction of demands that are based on the needs of the care recipient (Gordon, Pruchno, Wilson-Genderson, Murphy \& Rose, 2012). Women with elder care responsibilities report lower job security, receive lower levels of supervisory support, including reduced access to flexible working arrangements (Gordon et al., 2012). Organizational assistance in this regard helps employees to cope with their family circumstances (Anderson et al., 2002).

Employee wellness: Employee Assistance Programs (EAPs) provide assistance and information on personal matters (family and health) and work matters (work demands and work-life balance) that influence employee performance and well-being (Kinder et al., 2008). EAPs identifies employee concerns and designs interventions for this, and other services include counseling, financial support, child and eldercare services and health information (Kinder et al., 2008). Problems that are addressed across an entire spectrum makes for a happier and healthier employee (Pallarito, 2006). Integrated programs provide employees with a single point of contact to access services and coordinate the provision of services relating to employee wellness and work-life balance (Pallarito, 2006). Today, employers have shifted focus to the strategic value of promoting work-life balance, considering the impact it has on employee engagement and overall organisational performance (Lazar, Osoian, \& Ratiu, 2010).

Aim of the study: The aim of the study is to assess whether work intensification is a stumbling block to work-life balance in a public sector organization. The constructs for work intensification (organizational and technological change, work intensity and ergonomic factors, work-related stress and psychological factors, volume of workload and job insecurity) and for work-life balance (work-family conflict, work flexibility, managerial/supervisory support, child/elderly care and employee wellness) were explored.

\section{Methodology}

Research approach: The research methodology has been designed to assess employee perceptions on whether work intensification is a stumbling block to work-life balance in a public sector organization.

Respondents: The study was undertaken in a public sector organization, in KwaZulu-Natal, South Africa. Respondents were office-level employees and, the sample comprised of both male and female respondents of varying age, marital and race groups, with varying educational qualifications and years of service. Due to 
questionnaire apathy, the adequacy of the sample for work-life balance was determined using the KaiserMeyer-Olkin Measure of Sampling Adequacy (0.573) and the Bartlet's Test of Spherecity (965.610, p = 0.000). Similarly, the adequacy of the sample for work intensification was also determined using the Kaiser-MeyerOlkin Measure of Sampling Adequacy (0.626) and the Bartlet's Test of Spherecity (978.130, p = 0.000). The questionnaire was self-developed and a simple random sampling method was utilized. The majority of the sample comprised of $54 \%$ female employees, with $46 \%$ being male and $15 \%$ were managers, $18 \%$ were supervisors, $65 \%$ were employees and $2 \%$ constituted nil responses. In terms of age, $13 . \%$ were under 25 years of age, $39 \%$ were between $25-34$ years, $31 \%$ were between $35-44$ years, and $17.0 \%$ were 45 years and above. In terms of race $8 \%$ were Coloured employees, $11 \%$ were White, $24 \%$ were Indian and $57 \%$ were African in this organization. In addition, $13 \%$ of employees had a standard 8-10 qualification, $37 \%$ had a Diploma certificate, $18 \%$ had undergraduate degrees, 29.05 had post-graduate degrees, $2 \%$ had Postgraduate Diploma/Certificate and there were no responses from $1 \%$ of the employees. In addition, $43 \%$ were $0-5$ years in the organization, $18 \%$ were 6.10 years, $18 \%$ were $11-15$ years, $9 \%$ were $16-20$ years and $11 \%$ were 21 years. With regard to the number of children, $28 \%$ had one child, $22 \%$ had two children, $12 \%$ had three children, $2 \%$ had four children and over and lastly $36 \%$ had no children. In addition, $56 \%$ were single in this organization, $35 \%$ were married, $6 \%$ were divorced and $3 \%$ were widowed.

Measuring instrument: A self-developed questionnaire was utilized. Section A constitutes the demographic data which is measured using a nominal scale with pre-coded option categories. The items for Section B consist of 55, of which 30 items related to work intensification and; 25 items related to work-life balance. Items were measured using a 5-point Likert scale constituting strongly disagree (1), disagree (2), neutral (3), agree (4) and strongly agree (5). Pilot testing were conducted and the same protocol was adopted for the distribution of the main sample. The pilot testing confirmed that the questionnaire was appropriate with relevance and construction.

Measures: The validity of Section B was assessed using Factor Analysis. A principal component analysis was used to extract initial factors and an iterated principal factor analysis was performed using SPSS with an Orthogonal Varimax Rotation. Only items with loadings $>0.4$ were considered to be significant. Factors with latent roots greater than unity were extracted from the factor loading matrix. The results from the Factor Analysis confirm the validity of the instrument (Table 1).

Table 1: Factor Analysis - Validity of the instrument

\begin{tabular}{|c|c|c|c|c|c|c|}
\hline \multicolumn{4}{|c|}{ Work-life balance } & \multicolumn{3}{|c|}{ Work intensification } \\
\hline Factor & Eigenvalue & $\begin{array}{l}\% \quad \text { of } \\
\text { Variance }\end{array}$ & Total & Factor & Eigenvalue & $\begin{array}{l}\text { \% of Total } \\
\text { Variance }\end{array}$ \\
\hline 1 & 3.34 & 13.35 & & 1 & 3.84 & 12.39 \\
\hline 2 & 3.04 & 12.18 & & 2 & 2.62 & 8.46 \\
\hline 3 & 2.83 & 11.30 & & 3 & 2.33 & 7.50 \\
\hline 4 & 2.14 & 8.56 & & 4 & 2.27 & 7.33 \\
\hline \multirow[t]{2}{*}{5} & 2.08 & 8.33 & & 5 & 2.17 & 6.99 \\
\hline & & & & 6 & 2.80 & 6.71 \\
\hline
\end{tabular}

The reliability of the questionnaire was determined using Cronbach's Coefficient Alpha. The overall alpha coefficient for work intensification was 0.616 indicating internal consistency and reliability. The overall alpha coefficient for work-life balance was 0.590 , also showing internal consistency and reliability (Table 2).

Table 2: Reliability - Work Intensification and Work-life Balance

\begin{tabular}{ll}
\hline Work Intensification & Work-life Balance \\
\hline Cronbach's Coefficient Alpha & Cronbach's Coefficient Alpha \\
0.616 & 0.590 \\
\hline
\end{tabular}

Administration of the measuring instrument: The time frame was three months for the administration of the questionnaires which was conducted by an employee of the organization. Electronic and hard copies were utilized. 
Statistical analysis: Descriptive and inferential statistics were utilized for the analysis of the quantitative data. The data collected was captured on Excel and the Statistical Package for Social Sciences (SPSS) was used to perform all statistical analyses. The results were presented using tabular and graphical representations.

\section{Results}

Employees were expected to respond to the constructs relating to work intensification and work-life balance using a 5 point Likert scale, which were analysed using descriptive statistics (Table 3 ).

Table 3: Descriptive Statistics-Dimensions \& Sub-dimensions of Work Intensification and Work-life Balance

\begin{tabular}{|c|c|c|c|c|c|c|c|}
\hline Dimension & Mean & $\begin{array}{l}95 \% \\
\text { Interval } \\
\text { Lower } \\
\text { Bound }\end{array}$ & $\begin{array}{l}\text { Confidence } \\
\text { Upper } \\
\text { Bound }\end{array}$ & Variance & $\begin{array}{l}\text { Std. } \\
\text { Dev. }\end{array}$ & Min. & Max. \\
\hline Work Intensification & & & & & & & \\
\hline Organizational Change & 3.37 & 3.23 & 3.51 & 0.519 & 0.720 & 1.00 & 5.00 \\
\hline $\begin{array}{l}\text { Technological } \\
\text { Change }\end{array}$ & 2.84 & 2.74 & 2.95 & 0.278 & 0.527 & 1.00 & 4.00 \\
\hline $\begin{array}{l}\text { Ergonomic } \\
\text { Factors }\end{array}$ & 3.54 & 3.40 & 3.67 & 0.457 & 0.676 & 2.00 & 5.00 \\
\hline $\begin{array}{l}\text { Work-related Stress \& } \\
\text { Psychological Factors }\end{array}$ & 2.75 & 2.62 & 2.88 & 0.424 & 0.651 & 1.00 & 5.00 \\
\hline Volume of Workload & 3.43 & 3.30 & 3.56 & 0.421 & 0.649 & 1.00 & 5.00 \\
\hline Job Insecurity & 3.10 & 2.96 & 3.24 & 0.485 & 0.697 & 0 & 4.00 \\
\hline $\begin{array}{l}\text { Work-life Balance } \\
\text { Work-family Conflict } \\
\text { Work Flexibility }\end{array}$ & $\begin{array}{l}2.71 \\
3.63\end{array}$ & $\begin{array}{l}2.59 \\
3.47\end{array}$ & $\begin{array}{l}2.83 \\
3.79\end{array}$ & $\begin{array}{l}0.349 \\
0.650\end{array}$ & $\begin{array}{l}0.590 \\
0.806\end{array}$ & $\begin{array}{l}1.00 \\
1.00\end{array}$ & $\begin{array}{l}4.00 \\
5.00\end{array}$ \\
\hline $\begin{array}{l}\text { Managerial/ } \\
\text { Supervisory Support }\end{array}$ & 3.37 & 3.19 & 3.55 & 0.801 & 0.895 & 1.00 & 5.00 \\
\hline Child/Elderly Care & 2.99 & 2.87 & 3.10 & 0.327 & 0.572 & 1.00 & 4.00 \\
\hline Employee Wellness & 3.44 & 3.31 & 3.58 & 0.474 & 0.688 & 2.00 & 5.00 \\
\hline
\end{tabular}

Table 3 indicates the varying degrees on work intensification, based on mean analysis. Against a maximum attainable score of 5, there is room for improvement for each dimension. Ergonomic factors, which are fairly high, require the least amount of improvement as opposed to work-related stress and psychological factors. Top managers need to ensure that ergonomics factors are addressed for employees' comfort. Employees cope with volume of workload, despite an increase. This can be assessed as employees work beyond the normal work hours. There is room for improvement with organizational change and; new reporting structures and prompt dissemination of information addresses such concerns. Technological change and work-related stress and psychological factors require the greatest attention. Training must accompany new technology and, by assessing the increased responsibility, stress levels can be minimized. In addition, with work-life balance factors, work flexibility, followed by employee wellness requires the least improvement in contrast to workfamily conflict. The flexibility and freedom of choice over work arrangements contribute to reduced absenteeism and employee loyalty. An interactive wellness forum is advisable to share health-related information. Although managerial/supervisory support is moderate, a supportive work climate with emphasis on organizational culture and values are needed. Greater attention is required with child/elderly care and; the needs of working parents and those with care giving responsibilities must be considered. Workshops facilitated by professional coaches solve many problems with work-family conflict.

Frequency analyses were also computed for the sub-dimensions of the study. In this regard, $68 \%$ of employees agree that with changes, the content of their jobs have changed; whereas $22 \%$ disagree that as 
new staff join the organization, new reporting structures come into place. Also, $70 \%$ of employees agree that with technological change their work revolves heavily with computer work which involves prolonged periods of sitting; whereas $67 \%$ disagree those technological advancements have led to the demand for speedy responses with work matters. With work intensity and ergonomic factors, $76 \%$ agree that they make adjustments to their work space when performing their duties; whereas $19 \%$ disagree that staff feel free to address problems regarding ergonomically supportive work stations. With work-related stress and psychological factors, $63 \%$ agree that a certain level of work stress compels them to exert greater effort; whereas $57 \%$ disagree that an increase in responsibility leads to their stress levels. Also, $81 \%$ agree that they are able to cope with work even if their workload volume increases; and $60 \%$ disagree that there are times when the quantity of their workload compels them to work beyond the normal work hours. In addition, $63 \%$ of employees agree that they are willing to accept a job change so that their financial security is intact; whereas 34\% disagree that with job insecurity their overall well-being is negatively affected. With regard to work-family conflict, 55\% agree that there are days when employees experience work-family conflict which affects their quality of life. Furthermore, $69 \%$ disagree that they are constantly trying to avoid conflict with their work and personal life. In addition, 77\% agree that flexible work helps employees to balance work with family life, effectively and; only $7 \%$ disagree that a compressed work week can help employees to achieve a better work-life balance. With managerial/supervisory support, $61 \%$ agree that supervisors strive to ensure that staff performs optimally. On the contrary, $17 \%$ disagree that supervisors consider flexibility when considering home activities. In addition, $63 \%$ of employees agree that employee wellness is a top organizational priority; whereas $21 \%$ disagree that staff are given the chance to partake in decision-making with employee wellness.

Hypothesis 1: There exists significant inter-correlations amongst the sub-dimensions of work intensification (organizational and technological change, work intensity and ergonomic factors, work-related stress and psychological factors, volume of workload and job insecurity), respectively.

Table 4: Intercorrelations: sub-dimensions of Work Intensification

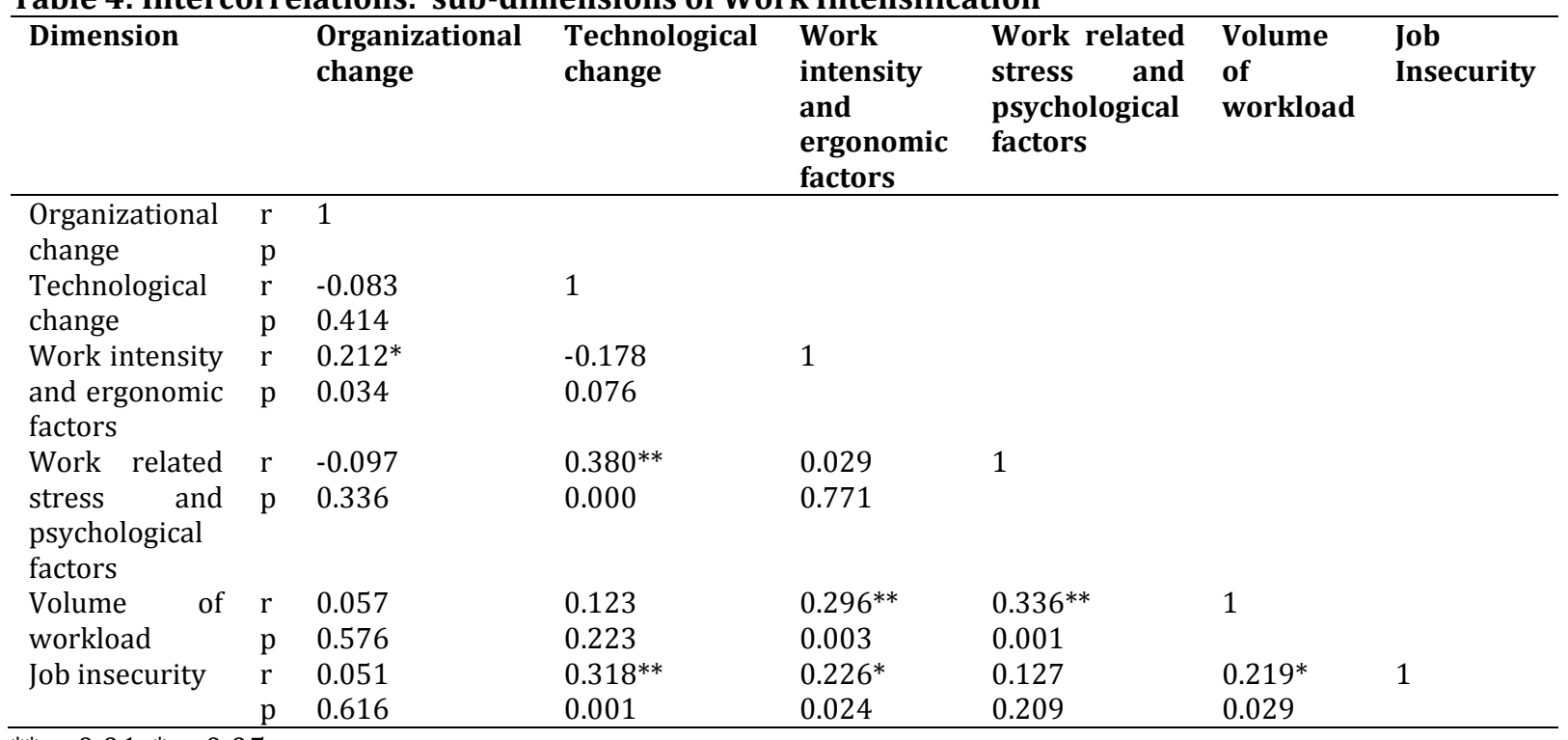

${ }^{* *} \mathrm{p}<0.01,{ }^{*} \mathrm{p}<0.05$

Table 4 reflects the inter-correlations with the sub-dimensions of work intensification:

- Organizational change correlates significantly but inversely with work intensity and ergonomic factors at the $5 \%$ level of significance. Technological change correlates significantly with workrelated stress and job insecurity respectively at the $1 \%$ level of significance.

- Work intensity and ergonomic factors correlates significantly with volume of workload at the $1 \%$ level of significance. Work intensity and ergonomic factors correlate significantly with job insecurity at the $5 \%$ level of significance respectively.

- Work-related stress correlates significantly with volume of workload at the $1 \%$ level of significance. 
- Volume of workload correlates significantly with job insecurity at the $5 \%$ level of significance. Hence, hypothesis 1 may be partially accepted.

Hypothesis 2: There exists significant inter-correlations amongst the sub-dimensions of work-life balance (work-family conflict, work flexibility, managerial/supervisory support, child/elderly care and employee wellness), respectively.

Table 5: Inter-correlations: sub-dimensions of Work-life Balance

\begin{tabular}{lllllll}
\hline $\begin{array}{l}\text { Work-life } \\
\text { balance }\end{array}$ & $\begin{array}{l}\text { Work- } \\
\text { family } \\
\text { conflict }\end{array}$ & $\begin{array}{l}\text { Work } \\
\text { Flexibility }\end{array}$ & $\begin{array}{l}\text { Managerial/ } \\
\text { Supervisory } \\
\text { support }\end{array}$ & $\begin{array}{l}\text { Child/Elderly } \\
\text { Care }\end{array}$ & $\begin{array}{l}\text { Employee } \\
\text { Wellness }\end{array}$ \\
\hline Work-family & $\mathrm{r}$ & 1 & & & \\
conflict & $\mathrm{p}$ & & & & \\
Work Flexibility & $\mathrm{r}$ & 0.110 & 1 & & \\
& $\mathrm{p}$ & 0.274 & & & \\
Managerial/Super- & $\mathrm{r}$ & -0.034 & $-0.267^{* *}$ & 1 & \\
visory support & $\mathrm{p}$ & 0.738 & 0.007 & & \\
Child/Elderly Care & $\mathrm{r}$ & -0.040 & -0.023 & $0.232^{*}$ & 1 \\
& $\mathrm{p}$ & 0.696 & 0.818 & 0.020 & \\
Employee & $\mathrm{r}$ & -0.115 & -0.103 & $0.209^{*}$ & $0.218^{*}$ & 1 \\
Wellness & $\mathrm{p}$ & 0.255 & 0.308 & 0.036 & 0.029 & \\
\hline
\end{tabular}

Table 5 reflects the inter-correlations with the sub-dimensions of work-life balance:

- Work flexibility correlates inversely with managerial/supervisory support at the $1 \%$ level of significance.

- Managerial/supervisory support correlates with child/elderly care and, with employee wellness at the $5 \%$ level of significance, respectively.

- Child/elderly care correlates with employee wellness at the $5 \%$ level of significance.

Hence, hypothesis 2 may be partially accepted.

Hypothesis 3: The sub-dimensions of work intensification significantly inter-correlate with the subdimensions of work-life balance.

Table 6: Correlations: sub-dimensions of work intensification and work-life balance

\begin{tabular}{|c|c|c|c|c|c|c|}
\hline \multicolumn{2}{|l|}{ Dimensions } & $\begin{array}{l}\text { Work-family } \\
\text { conflict }\end{array}$ & $\begin{array}{l}\text { Work } \\
\text { Flexibility }\end{array}$ & $\begin{array}{l}\text { Managerial/ } \\
\text { Supervisory } \\
\text { support }\end{array}$ & $\begin{array}{l}\text { Child/Elderly } \\
\text { Care }\end{array}$ & $\begin{array}{l}\text { Employee } \\
\text { Wellness }\end{array}$ \\
\hline Organisational & $\mathrm{r}$ & -0.061 & 0.018 & $0.197^{*}$ & 0.131 & 0.009 \\
\hline change & $\mathrm{p}$ & 0544 & 0.859 & 0.049 & 0.195 & 0.933 \\
\hline $\begin{array}{l}\text { Technological } \\
\text { change }\end{array}$ & $\begin{array}{l}r \\
p\end{array}$ & $\begin{array}{l}0.368^{* *} \\
0.000\end{array}$ & $\begin{array}{l}0.132 \\
0.190\end{array}$ & 0.149 & 0.062 & -0.155 \\
\hline & & & & 0.138 & 0.537 & 0.124 \\
\hline $\begin{array}{l}\text { Work intensity and } \\
\text { ergonomic factors }\end{array}$ & $\begin{array}{l}\mathrm{r} \\
\mathrm{p}\end{array}$ & $\begin{array}{l}-0.254^{*} \\
0.011\end{array}$ & $\begin{array}{l}0.021 \\
0.837\end{array}$ & $0.393^{* *}$ & 0.181 & 0.087 \\
\hline & & & & 0.000 & 0.072 & 0.391 \\
\hline $\begin{array}{l}\text { Work-related stress } \\
\text { and psychological }\end{array}$ & $\begin{array}{l}\mathrm{r} \\
\mathrm{p}\end{array}$ & $\begin{array}{l}0.533^{* *} \\
0.000\end{array}$ & $\begin{array}{l}0.090 \\
0.372\end{array}$ & $0.232^{*}$ & $0.331^{* *}$ & 0.159 \\
\hline factors & & & & 0.020 & 0.001 & 0.115 \\
\hline $\begin{array}{l}\text { Volume of work- } \\
\text { load }\end{array}$ & $\begin{array}{l}\mathrm{r} \\
\mathrm{p}\end{array}$ & $\begin{array}{l}0.062 \\
0.540\end{array}$ & $\begin{array}{l}0.264^{* *} \\
0.008\end{array}$ & $0.332^{* *}$ & 0.025 & 0.174 \\
\hline & & & & 0.001 & 0.807 & 0.083 \\
\hline Job insecurity & $\begin{array}{l}\mathrm{r} \\
\mathrm{p}\end{array}$ & $\begin{array}{l}-0.042 \\
0.678 \\
\end{array}$ & $\begin{array}{l}0.195 \\
0.052 \\
\end{array}$ & 0.015 & 0.041 & 0.123 \\
\hline
\end{tabular}




\section{Journal of Economics and Behavioral Studies (ISSN: 2220-6140)}

Vol. 9, No. 5, pp. 230-243, October 2017

0.886

0.686

0.224

Table 6 reflects the following correlations and hence, hypothesis 3 maybe partially accepted:

- Work-family conflict correlates with technological change and, with work-related stress and psychological factors at the $1 \%$ level of significance. Work-family conflict correlates inversely with work intensity and ergonomic factors at the $5 \%$ level of significance.

- Work flexibility correlates with volume of workload at the $1 \%$ level of significance.

- Managerial/supervisory support correlates with work intensity and ergonomic factors and, with volume of workload at the $1 \%$ level of significance. Managerial/supervisory support correlates with organizational change and work-related stress and psychological factors at the $5 \%$ level of significance.

- Child/elderly care correlates with work-related stress and psychological factors at the $1 \%$ level of significance.

Table 7: Correlation (Spearman's rho): Work Intensification and Work-life Balance

\begin{tabular}{llll}
\hline Dimension & & $\mathbf{r} / \mathbf{p}$ & Dimensions of Work-life Balance \\
\hline Dimensions of Work & $\mathrm{r}$ & 1 & \\
Intensification & $\mathrm{p}$ & & \\
Dimensions of Work-life & $\mathrm{r}$ & 0.399 & 1 \\
Balance & $\mathrm{p}$ & $0.000^{* *}$ & \\
\hline
\end{tabular}

Table 7 reflects that there is a significant relationship between work intensification and work-life balance. Hence, hypothesis 3 is confirmed at the $1 \%$ level of significance.

Hypothesis 4: The dimensions and sub-dimensions of work intensification significantly account for the variance in determining employee perceptions of work intensification.

Table 8: Multiple Regression: The Effect of Work-life Balance Factors on Work Intensification

\begin{tabular}{|c|c|c|c|c|c|}
\hline Model & \multicolumn{2}{|l|}{$\mathbf{R}$} & R Square & $\begin{array}{l}\text { Adjusted } \\
\text { R Square }\end{array}$ & $\begin{array}{l}\text { Std. Error of } \\
\text { the Estimate }\end{array}$ \\
\hline 1 & \multicolumn{2}{|l|}{$0.359 \underline{a}$} & 0.129 & 0.120 & 0.33504 \\
\hline \multirow[t]{3}{*}{2} & \multicolumn{2}{|l|}{$0.423^{b}$} & 0.179 & 0.162 & 0.32697 \\
\hline & \multicolumn{2}{|c|}{ Unstandardized } & Standardized & & \\
\hline & Coeffic & & Coefficients & & \\
\hline Model & B & Std. Error & Beta & $\mathbf{t}$ & $\mathbf{P}$ \\
\hline 1 (Constant) & 2.689 & 0.131 & & 20.508 & 0.000 \\
\hline $\begin{array}{l}\text { Managerial/Supervisory } \\
\text { Support }\end{array}$ & 0.143 & 0.038 & 0.359 & 3.804 & 0.000 \\
\hline \multirow{2}{*}{$\begin{array}{ll}2 & \text { (Constant) } \\
\text { Managerial/Supervisory } \\
\text { Support }\end{array}$} & 2.233 & 0.205 & & 11.201 & 0.000 \\
\hline & 0.150 & 0.037 & 0.376 & 4.070 & 0.000 \\
\hline Work-family Conflict & 0.136 & 0.056 & 0.224 & 2.428 & 0.017 \\
\hline \multicolumn{6}{|l|}{ Excluded Variables } \\
\hline Employee Wellness & -0.016 & -0.169 & 0.866 & -0.017 & 0.939 \\
\hline Work Flexibility & 0.129 & 1.337 & 0.184 & 0.135 & 0.905 \\
\hline Child/Elderly Care & 0.160 & 1.686 & 0.095 & 0.170 & 0.926 \\
\hline
\end{tabular}

Evidently $12 \%$ of the variance in work intensification (Table 8) is due to the effect of work-life balance factors. In addition, two sub-dimensions of work-life balance significantly account for the variance at the 5\% level of significance, and these factors include managerial/supervisory support and, work-family conflict. The Beta values in Table 6 indicate that managerial/supervisory support (Beta $=0.376$ ) has a negligibly higher impact on work-life balance than work-family conflict (Beta= 0.224). Hence, hypothesis 4 is accepted. Caution is expressed with regards to the low $R$ square value especially when used for the purpose of prediction. 
Hypothesis 5: The dimensions and sub-dimensions of work life balance significantly account for the variance in determining work-life balance in this organization.

Table 9: Multiple Regression: The Effect of Work Intensification factors on Work-life Balance

\begin{tabular}{|c|c|c|c|c|c|}
\hline Model & \multicolumn{2}{|l|}{$\mathbf{R}$} & R Square & $\begin{array}{l}\text { Adjusted } \\
\text { R Square }\end{array}$ & $\begin{array}{l}\text { Std. Error of } \\
\text { the Estimate }\end{array}$ \\
\hline 1 & \multicolumn{2}{|l|}{$0.514^{\mathrm{a}}$} & 0.265 & 0.257 & 0.31839 \\
\hline \multirow[t]{2}{*}{2} & \multirow{2}{*}{\multicolumn{2}{|c|}{$\begin{array}{l}0.543^{\mathrm{b}} \\
\text { Unstandardized } \\
\text { Coefficients }\end{array}$}} & 0.295 & 0.281 & 0.31330 \\
\hline & & & $\begin{array}{l}\text { Standardized } \\
\text { Coefficients }\end{array}$ & & \\
\hline Model & B & Std. Error & Beta & $\mathbf{t}$ & $\mathbf{p}$ \\
\hline $\begin{array}{ll}1 & \text { (Constant) } \\
& \text { Work-related Stress \& }\end{array}$ & 2.425 & 0.139 & & 17.488 & 0.000 \\
\hline Psychological Factors & 0.292 & 0.049 & 0.514 & 5.937 & 0.000 \\
\hline $\begin{array}{ll}2 & \text { (Constant) } \\
& \text { Work-related Stress \& }\end{array}$ & 2.172 & 0.184 & & 11.799 & 0.000 \\
\hline Psychological Factors & 0.248 & 0.053 & 0.438 & 4.706 & 0.000 \\
\hline Volume of Workload & 0.109 & 0.053 & 0.191 & 2.053 & 0.043 \\
\hline \multicolumn{6}{|l|}{ Excluded Variables } \\
\hline Technological Change & 0.046 & 0.490 & 0.626 & 0.050 & 0.841 \\
\hline $\begin{array}{l}\text { Job Insecurity } \\
\text { Work Intensity \& }\end{array}$ & -0.041 & -0.473 & 0.638 & -0.048 & 0.961 \\
\hline Ergonomic Factors & 0.096 & 1.067 & 0.289 & 0.108 & 0.902 \\
\hline Organizational Change & 0.123 & 1.437 & 0.154 & 0.145 & 0.976 \\
\hline
\end{tabular}

Table 9 indicates that $26 \%$ of the variance in work-life balance is due to the effect of work intensification factors. Furthermore, work-related stress and psychological factors and, volume of workload significantly account for the variance at the $5 \%$ level of significance. The Beta values indicate that work-related stress and psychological factors (Beta $=0.438$ ) has a considerably higher impact on work intensification than volume of workload (Beta= 0.191). Hence, hypothesis 5 is accepted. However, caution is shown with regards to the low $\mathrm{R}$ square value especially when used for the purpose of prediction.

\section{Conclusion and Recommendations}

It is recommended that with regard to work intensity and ergonomic factors the organization must consider employees' working capacity by accommodating their needs. By consulting an ergonomics committee many problems are solved especially with their valuable input in design principles. Down (2001) emphasizes that ergonomics optimizes employees' working conditions in terms of safety and performance. Furthermore, in order to reduce the volume of workload timeous workload reviews is needed for workload re-distribution. Workload is a source of mental stress that involves the intensity of job assignments (Shah, Jaffari, Aziz, Ejaz, Ul-Haq \& Raza, 2011) and; workers are compelled to work harder and faster (Burchell et al., 2002). The prompt dissemination of information on organizational change must be practiced to create awareness and; strategic initiatives, such as training must be in place. Arrowsmith (2003) opines that the internationalization of competition coupled with merger and acquisition are amongst the major transformations occurring. With job insecurity, timeous communication on managers' assurance must be provided on employee status and the future existence of their jobs. Additionally, De Witte (2005) opines that job insecurity contributes to employees' helplessness. Technological changes necessitate the training of employees for a transition to new ways of working. It is recommended that work be re-allocated to reduce the burden of work intensification that comes with technological changes. Naswall et al. (2008) assert that new technology can also render jobs less labour-intensive.

Work-related stress and psychological factors are compelling factors that must be addressed to create the following: a comfortable work atmosphere; social support activities (team retreats) for stress reduction; self- 
assessments on stress levels to generate awareness and coping strategies; employee training to develop problem-solving and conflict management skills to reduce stress. When the relationship between employees and their environment exceeds their resources and jeopardizes their well-being, this is the psychological nature of stress (Burchell et al., 2002). It is recommended that managers institute work flexibility for a content workforce and for the freedom of choice over work arrangements to reduce absenteeism and; for results to be in line with financial performance and quality improvements. In line with this, Jang (2009) opines that employee perceptions on the flexibility of work schedules are enhanced with supervisors and supportive cultures. Voluntary support group sessions to stimulate open discussions, including an online interactive wellness forum must be instituted as a strategic initiative for employee wellness. Many employers are interested in health and productivity due to the added costs that come with employee illness, absenteeism, and costs with recruiting and retaining top talent (Mudge-Riley, McCarthy, \& Persichetti, 2013). With managerial/supervisory support organizational values must be emphasized, including a work climate for collaboration and employee engagement. With supportive supervisors or managers it is less likely for employees to experience work-family conflict (Gordon et al., 2012).

A supportive work environment must be instituted to accommodate child/elderly care assistance with an onsite day care facility and; adopting a work climate to share workloads so that elderly care responsibilities is accommodated. Working and caring for an older person is an intense experience due to the conditions of elder care responsibilities which can occur with a crisis and with this increasing over time (Gordon et al., 2012). Furthermore, the organization must foster a supportive workplace culture for engagement with worklife balance initiatives to address the concerns of work-family conflict. The organization can employ a psychologist, institute special leave policy and hold on-site workshops facilitated by professional life coaches. Work-family conflict impacts on the mental health negatively which includes depression and anxiety disorders (Kelly \& Moen, 2007).

With the implementation of the above recommendations relating to work intensification and work-life balance the organization would overcome numerous obstacles. Furthermore, the study, based on full-time office workers reveals that work intensification and work-life balance can be conducted in organizations other than labour intensive ones. Managers need to take cognizance of, for example, technological change and organizational changes which impacts employees' job content and functions. Public sector organizations need to readdress the volume of employees' workload. With their obsessional commitment, managers need to adjust the work environment to accommodate work demands and non-work responsibilities including the provisions of child and elderly care support. The variance in work-life balance was due to the effect of work intensification factors. Work-related stress and psychological factors had a considerably higher impact on work intensification than volume of workload. Similarly, the variance in work intensification was due to the effect of work-life balance factors. Managerial/supervisory support had a slightly higher impact on work-life balance than work-family conflict. The study is significant for practical reasons and managers need to use these fundamental points to probe assumptions and shift boundaries. Organizations and policy makers need to seriously consider the implications associated with the effect of work intensification on work-life balance.

\section{References}

Anderson, S. E., Coffey, B. S. \& Byerly, R. T. (2002). Formal organizational initiatives and informal workplace practices: Links to work-family conflict and job-related outcomes. Journal of Management, 28(6), 787-810.

Arrowsmith, J. (2003). Job insecurity and work intensification. Human Resource Management Journal, 13(1), 93-95.

Allvin, M., Aronsson, G., Hagström, T., Johansson, G. \& Lundberg, U. (2011). Work Without Boundaries: Psychological Perspectives on the New Working Life. United Kingdom: John Wiley \& Sons, Ltd.

Alnaser, M. Z. \& Wughalter, E. H. (2009). Effect of chair design on ratings of discomfort. Work, 34(2), 223-234. doi:10.3233/WOR-2009-0919.

Babu, S. \& Raj, K. B. (2013), Impact of Childcare Assistance (A Work-Life Balance Practice) on Employee Retention in Indian IT Sector. Global Journal of Management and Business Research Interdisciplinary, 13(6), 8-18. 
Burchielli, R., Pearson, P. \& Thanacoody, P. R. (2006). Exploring work intensification in teaching: A research agenda. New Zealand Journal of Employment Relations (Online), 31(2), 71-81. Retrieved April 28, 2014 from http://search.proquest.com/docview/ 233250067? accountid=11921.

Burchell, B., Lapido, D. \& Wilkinson, F. (2002). Job Insecurity and Work Intensification. London: Routledge

Burke, R. J., Singh, P. \& Fiksenbaum, L. (2010). Work intensity: potential antecedents and consequences. Personnel Review, 39(3), 347-360. doi:10.1108/00483481011030539.

Crompton, R. (2006). Employment and the family: The reconfiguration of work and family life in contemporary societies. New York: Cambridge University Press.

Dachapalli, L. P. \& Parumasur, S. B. (2012). Employee susceptibility to experiencing job insecurity. South African Journal of Economic and Management Sciences, 15(1), 31.

Dainoff, M. J. (2007). Ergonomics and health aspects of work with computer: International conference, EHAWC 2007, held as part of HCI International 2007, Beijing, China, July 22-27: Proceedings. Germany: Springer.

de Klerk, M. \& Mostert, K. (2010). Work-home Interference: Examining Socio-demographic Predictors in the South African Context. South African Journal of Human Resource Management, 8(1), 1-10. doi:10.4102/sajhrm.v8i1.203.

De De Witte, H. (2005). Job Insecurity: Review of the International Literature on Definitions, Prevalence, Antecedents and Consequences. SA Journal of Industrial Psychology, 31(4), 1-6.

Down, R. (2001). Getting the best out of the Ergonomics approach. The Safety \& Health Practitioner, 19(2), 3437. Retrieved April 29, 2014 from http://search.proquest.com/ docview/201006766?accountid=11921.

Forma, P. (2009). Work, family and intentions to withdraw from the workplace. International Journal of Social Welfare, 18(2), 183-192. doi:10.1111/j.1468-2397.2008.00585.x.

Gordon, J. R., Pruchno, R. A., Wilson-Genderson, M., Murphy, W. M. \& Rose, M. (2012). Balancing care giving and work: Role conflict and role strain dynamics. Journal of Family Issues, 33(5), 662-689.

Goulding, A. \& Kerslake, E. (1996). Flexible working in libraries: profit and potential pitfalls, Library Management, 17(2), 8-16.

Green, F. (2004). Why has work effort become more intense? Industrial Relations, 43(4), 709-741. doi:10.1111/j.0019-8676.2004.00359.x.

Green, F. (2004). Work Intensification, Discretion, and the Decline in Well-being at Work. Eastern Economic Journal, 30(4), 615-625. Retrieved July 11, 2013 from http://search.proquest.com/docview/198043823?accountid=11921.

Green, F. (2001). It's been a Hard Day's Night: The Concentration and Intensification of Work in Late Twentieth-Century Britain. British Journal of Industrial Relations, 39(1), 53-80.

Green, F. \& McIntosh, S. (2001). The intensification of work in Europe. Labour Economics, 8(2), 291-308. doi: 10.1016/S0927-5371(01)00027-6.

Hannabuss, S. (1998), Flexible jobs: changing patterns in information and library work. New Library World, 99(1141), 104-111.

Huang, Y., Du, P., Chen, C. \& Huang, I. (2011). Mediating Effects of Emotional Exhaustion on the Relationship Between Job Demand-Control Model and Mental Health. Stress \& Health, 27(2), 94-109.

James, A. (2011). Work-life (im) 'balance' and its consequences for everyday learning and innovation in the New Economy: evidence from the Irish IT sector. Gender, Place \& Culture: A Journal of Feminist Geography, 18(5), 655-684. doi:10.1080/0966369X.2011.601805.

Jang, S. J. (2009). Relationships of flexible work schedules, workplace support, supervisory support, work/life balance, and the well-being of working parents. Journal of Social Service Research, 3, 93-104.

Kelly, E. L. \& Moen, P. (2007). Rethinking the Clockwork of Work: Why Schedule Control May Pay Off at Work and at Home. Advances in Developing Human Resources, 9(4), 487-506.

Kinnunen, U., Geurts, S. \& Mauno, S. (2004). Work-to-family conflict and its relationship with satisfaction and well-being: a one-year longitudinal study on gender differences. Work and Stress, 18(1), 1-22.

Kinder, A., Hughes, R. \& Cooper, C. L. (Eds.). (2008). Employee Well-Being Support: A Workplace Resource. England: John Wiley \& Sons, Ltd.

Lauzun, H. M., Morganson, V. J., Major, D. A. \& Green, A. P. (2010). Seeking Work-Life Balance: Employees' Requests, Supervisors' Responses, and Organizational Barriers. Psychologist-Manager Journal (Taylor \& Francis Ltd), 13(3), 184-205. 
Lawton, L. (2010). Work-Family Balance, Family Structure and Family-Friendly Employer Programs. Retrieved June 20, 2013, from http://paa2010.princeton.edu/papers/100573.

Lazar, I., Osoian, C. \& Ratiu, P. (2010). The role of work-life balance practices in order to improve organizational performance. European Research Studies, 13(1), 201-213

Matthews, R. A., Swody, C. A. \& Barnes-Farrell, J. L. (2012). Work Hours and Work-Family Conflict: The Double-edged Sword of Involvement in Work and Family. Stress \& Health: Journal of the International Society for the Investigation of Stress, 28(3), 234-247.

May, D. R., Reed, K., Schwoerer, C. E. \& Potter, P. (2004). Ergonomic Office Design and Aging: A QuasiExperimental Field Study of Employee Reactions to an Ergonomics Intervention Program. Journal of Occupational Health Psychology, 9(2), 123-135.

Mudge-Riley, M., McCarthy, M. \& Persichetti, T. E. (2013). Incorporating Wellness Into Employee Benefit Strategies- Why It Makes Sense. Benefits Quarterly, 29(4), 30-34.

McNamara, T. K., Pitt-Catsouphes, M., Matz-Costa, C., Brown, M. \& Valcour, M. (2013). Across the continuum of satisfaction with work-family balance: Work hours, flexibility-fit, and work-family culture. Social Science Research, 42(2), 283-298.

Naswall, K., Hellgren, J. \& Sverke, M. (Eds.). (2008). The Individual in the Changing Working Life. New York: Cambridge University Press.

Nitzsche, A., Pfaff, H., Jung, J. \& Driller, E. (2013). Work-life balance culture, work-home interaction, and emotional exhaustion: A structural equation modeling approach. Journal of Occupational and Environmental Medicine, 55(1), 67-73.

O'Connor, M. A. (2005). Corporate Social Responsibility for Work/Family Balance. St. John's Law Review, 79(4), 1193-1220.

Pallarito, K. (2006). Overburdened and under-appreciated, school audiologists forge ahead. Hearing Journal, 59(9), 19-24.

Pasca, R. \& Wagner, S. L. (2011). Occupational Stress in the Multicultural Workplace. Journal of Immigrant Minority Health, 13(4), 697-705. doi:10.1007/s10903-011-9457-6

Pile, K. W. (2001). Approaching ergonomics in the new millennium. Pulp \& Paper, 75(9), 25.

Porter, G. \& Kakabadse, N. K. (2006). HRM perspectives on addiction to technology and work. Journal of Management Development, 25(6), 535-560.

Rehman, M. A. U., Haq, I. U., Jam, F. A., Ali, A. \& Hijazi, S. T. (2010). Psychological contract breach and burnout, mediating role of job stress and feeling of violation. European Journal of Social Sciences, 17(2), 232237.

Rothmann, S. (2008). Job satisfaction, occupational stress, burnout and work engagement as components of work-related wellbeing: empirical research. South African Journal of Industrial Psychology, 34(3), 1116. Retrieved April 23, 2013 from http://reference.sabinet.

Shah, S. S. H., Jaffari, A. R., Aziz, J., Ejaz, W., Ul-Haq, I. \& Raza, S. N. (2011). Workload and performance of employees. Interdisciplinary Journal of Contemporary Research in Business, 3(5), 256-267.

Singh, A. (2013). Female employees' perceptions of work-life balance at a banking institution in the Durban region. Unpublished Master's thesis, University of KwaZulu-Natal, Durban, South Africa.

Sonnentag, S. \& Bayer, U. (2005). Switching Off Mentally: Predictors and Consequences of Psychological Detachment From Work During Off-Job Time. Journal of Occupational Health Psychology, 10(4), 393414.

Sparks, K., Faragher, B. \& Cooper, C. L. (2001). Well-being and occupational health in the 21st century workplace. Journal of Occupational and Organizational Psychology, 74, 489-509.

Stranks, J. (2005). Stress at Work: Management and Prevention. Oxford, UK: Elsevier ButterworthHeinemann.

Subramanyam, M., Muralidhara, P. \& Pooja, M. (2013). Mental Workload and Cognitive Fatigue: A Study. IUP Journal of Management Research, 12(2), 29-39.

Sue Ling, L., Chang, J. \& Lien Yin, H. (2012). Does Effect of Workload on Quality of Work Life Vary With Generations? Asia Pacific Management Review, 17(4), 437-451. doi:10.6126/APMR.2012.17.4.06.

Sverke, M., Hellgren, J., Näswall, K., Chirumbolo, A., De Witte, H. \& Goslinga, S. (2004). Job insecurity and union membership. European unions in the wake of flexible production. Brussels: P.I.E.-Peter Lang.

Tayfur, 0.\& Arslan, M. (2013). The role of lack of reciprocity, supervisory support, workload and work-family conflict on exhaustion: Evidence from physicians. Psychology, Health \& Medicine, 18(5), 564-575. 


\section{Journal of Economics and Behavioral Studies (ISSN: 2220-6140)}

Vol. 9, No. 5, pp. 230-243, October 2017

Tucker, E., Kao, T. \& Verma, N. (2005). Next-Generation Talent Management: Insights on How Workforce Trends Are Changing the Face of Talent Management. Business Credit, 106(7), 20-27.

Van Wyk, M. \& Pienaar, J. (2008). Towards a research agenda for job insecurity in South Africa. Southern African Business Review, 12(2), 49-86. Retrieved June 11, 2013 from http://reference.sabinet.co.za/webx/access/electronic_journals/sabr/sabr_v12_n2_a3.pdf.

van Zyl, L., van Eeden, C. \& Rothmann, S. (2013). Job insecurity and the emotional and behavioural consequences thereof. South African Journal of Business Management, 44(1), 75-86.

Voydanoff, P. (2007). Work, Family and Community: Explaining Interconnections. New Jersey: Lawrence Erlbaum Associates Inc.

Walinga, J. \& Rowe, W. (2013). Transforming stress in complex work environments: Exploring the capabilities of middle managers in the public sector. International Journal of Workplace Health Management, 6(1), 66 - 88. http://dx.doi.org/ 10.1108/ 17538351311312420.

Waller, A. D. \& Ragsdell, G. (2012). The impact of e-mail on work-life balance. Aslib Proceedings: New Information Perspectives, 64(2), 154-177. doi:10.1108/00012531211215178.

Webber, M., Sarris, A. \& Bessell, M. (2010). Organizational Culture and the Use of Work-Life Balance Initiatives: Influence on Work Attitudes and Work-Life Conflict. Australian \& New Zealand Journal of Organizational Psychology, 3(1), 54-65. doi:10.1375/ajop.3.1.54. 